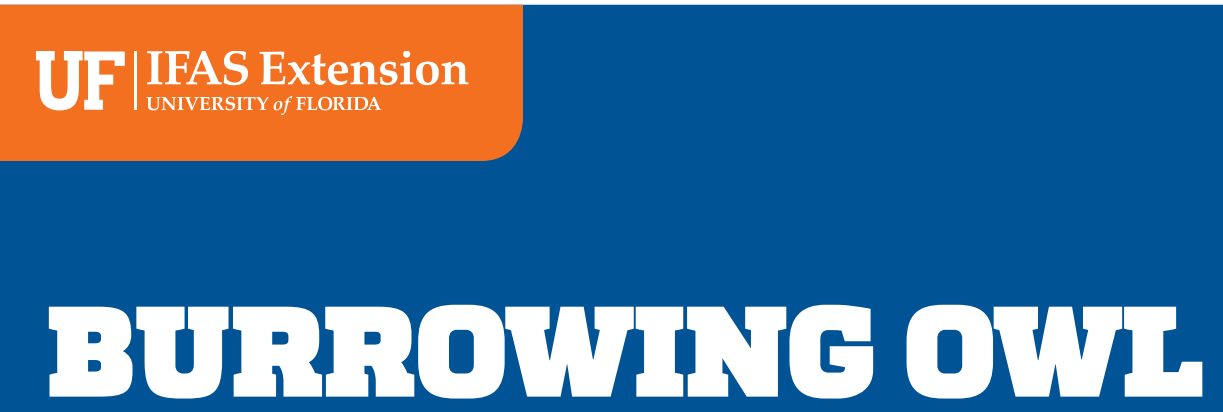

Julie Burford · Raoul Boughton

Wildlife of Florida Factsheets

The Owl “hoo” Loves Rangelands
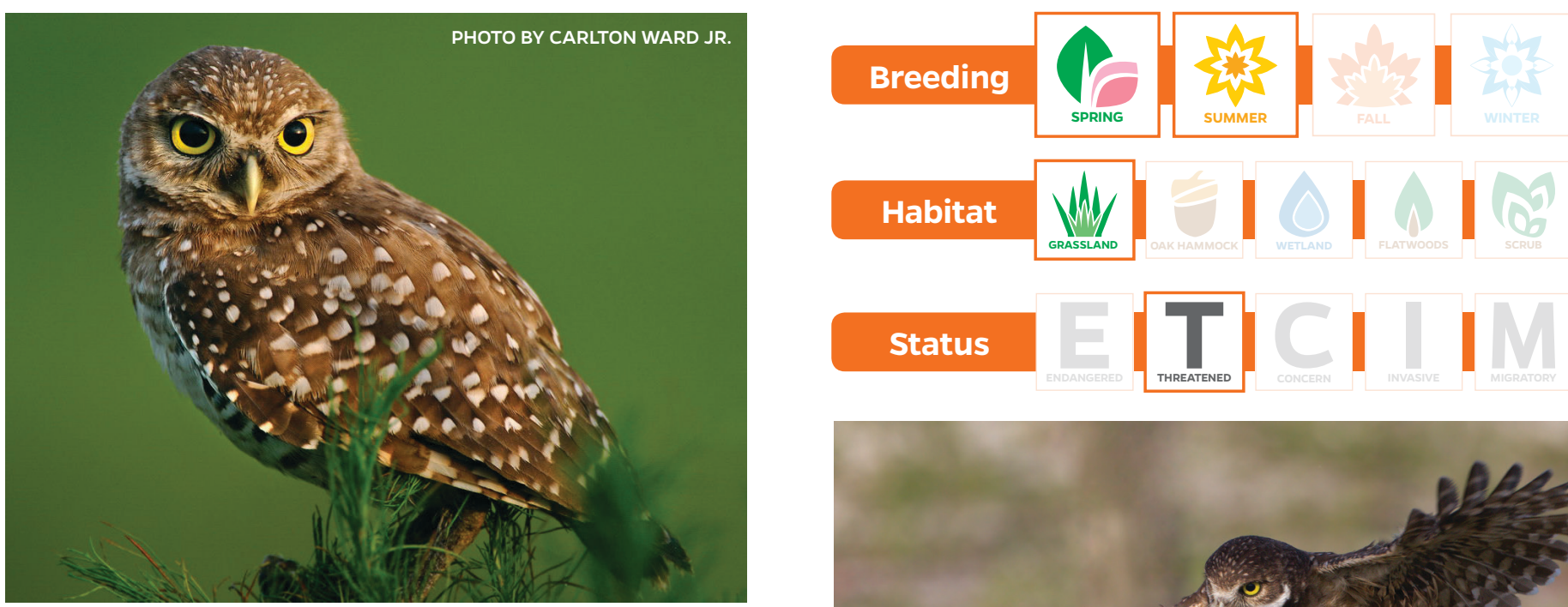

SCIENTIFIC NAME Athene cunicularia floridana

COMMON NAMES burrowing owl, ground owl

HABITAT Open-type habitats with short groundcover, including agricultural and urban areas.

PHYSICAL DESCRIPTION Smaller owl with long legs,

bright yellow eyes, and no ear tufts. Body length can reach 9 in and wing span 21 in.

\title{
WEIGHT 6 ounces
}

REPRODUCTIVE RATE 21-28 day incubation, 6-8 eggs,

fledge around 12 weeks.

LIFESPAN 6-8 years for western burrowing owls, unknown in Florida.

DISPERSAL \& HOME RANGE Unknown for Florida populations, however, research currently being conducted.

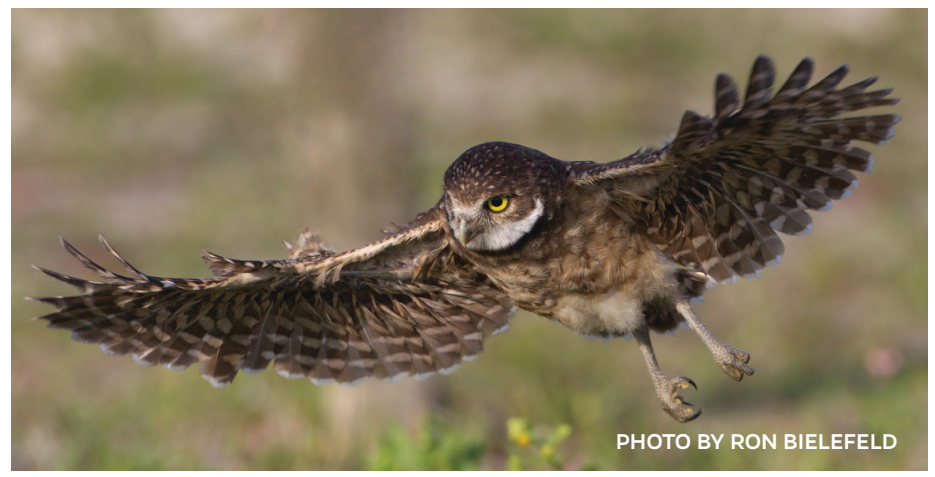

\section{Did You Know?}

Burrowing owls often decorate their burrow openings with dung, insect parts, feathers, grass clippings, paper, or other debris.

HISTORY AND HABITAT Owls were generally observed in the late 1800 s on dry prairies in south-central Florida. The low, grassy vegetation of historic dry prairies was maintained by periodic flooding and natural fires. Today, few native dry prairie habitats remain because of fire suppression and conversion to human land uses. Burrowing owls have since expanded their natural breeding range and are now found mostly on agricultural fields, airports, ball fields, and residential lots.
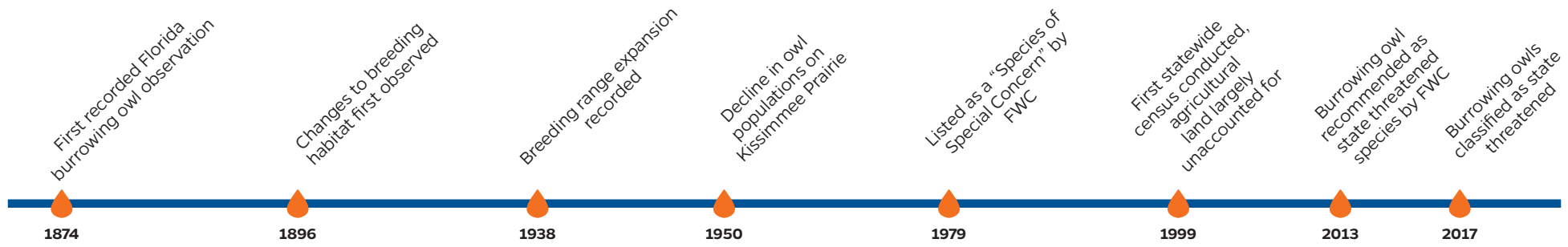


\section{BURAOHATE OWh Fistrighs}

- The burrowing owl population in Florida is a geographically distinct subspecies and unlike the western subspecies, they are nonmigratory. - Burrowing owls are active during the day and at night.

- They can hover in midair to catch food.

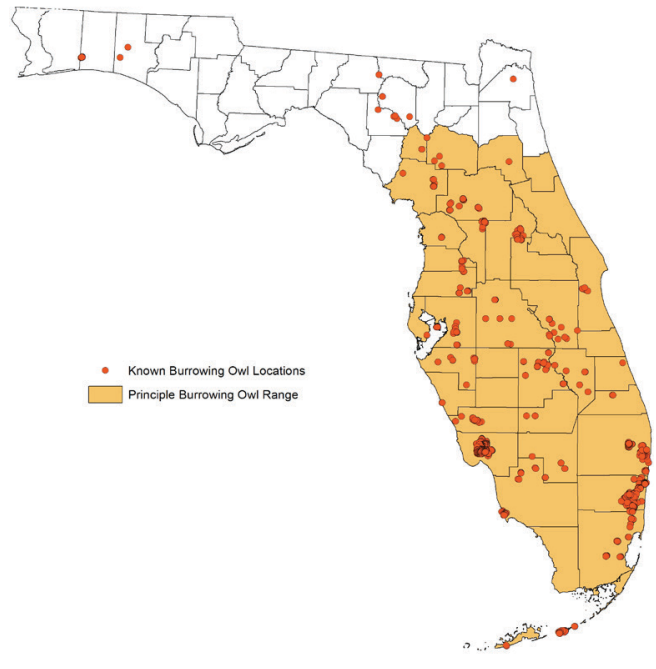

DISTRIBUTION Burrowing owls have expanded their range to north and south Florida due to human-induced landscape modifications. Their distribution is localized and spotty throughout peninsular Florida, with high concentrations occurring in urban SE coastal areas and Cape Coral. Small colonies have been found as far west as Eglin Air Force Base and as far south as the Dry Tortugas. Little is known about the distribution of burrowing owls on agricultural land, although owls are known to extensively use rangeland and other agricultural fields.

BIOLOGY AND BEHAVIOR Burrowing owls live as single breeding pairs, often forming loose colonies consisting of multiple families living within $500 \mathrm{ft}$ of each other. During the day, they are usually observed standing at the mouths of their burrows or on a nearby post. Florida burrowing owls typically dig their own burrows, but they are also known to use burrows of gopher tortoises (Gopherus polyphemus) or armadillos (Dasypus novemcinctus), and they sometimes occupy structures such as manholes, sewer drains, and concrete pipes. Their breeding season is typically February-July. Young owls emerge from the burrow at 2 weeks and stay with their parents for approximately 12 weeks. Burrowing owls primarily forage on insects, especially grasshoppers and beetles, though small lizards, frogs, snakes, birds, and rodents are also important prey items.

\section{How Kou can Fiplp}

- Install T perches near owl burrows to give owls an elevated view of their nest areas.

- Maintain low vegetation ( $<5$ inches) within 10 feet of burrow entrance using light equipment such as weed trimmers, except during nesting season.

- Avoid heavy equipment near active burrow openings to prevent collapsing burrows.

- Restrict the use of pesticides that may affect owl food sources.

-Keep pets away from the owls' burrow sites.

\section{IMPORTANCE OF RANGELAND FOR}

CONSERVATION Due to the many threats and decreasing availability of vacant lots in urban areas, rangelands appear to be critical to the burrowing owl's overall conservation. The current status of owls in these areas is unknown because researchers face difficulty accessing privately owned lands. Limited surveys may also result in population underestimation. Moderately grazed pastures provide the low-stature vegetation requirements for owl breeding habitat and may be preferable to more intensively developed areas.

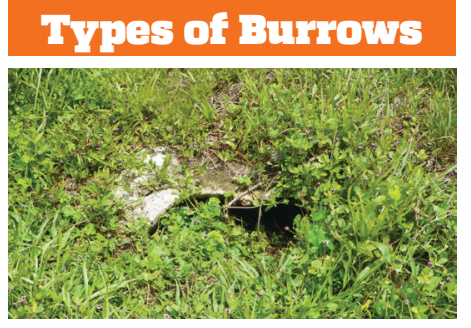

Burrow under limestone outcropping

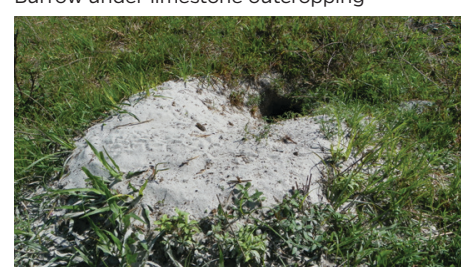

Burrow on open rangeland

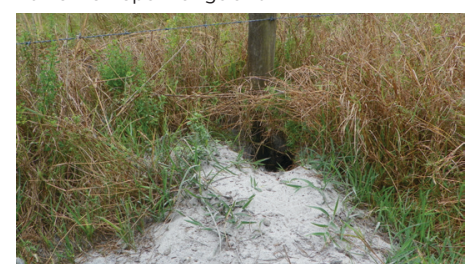

Burrow along fence line

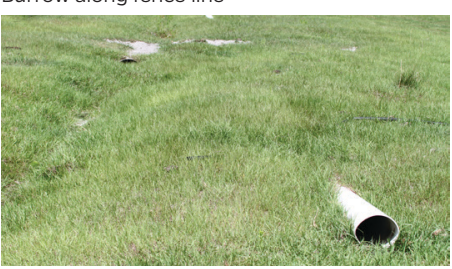

Burrow in abandoned PVC pipe

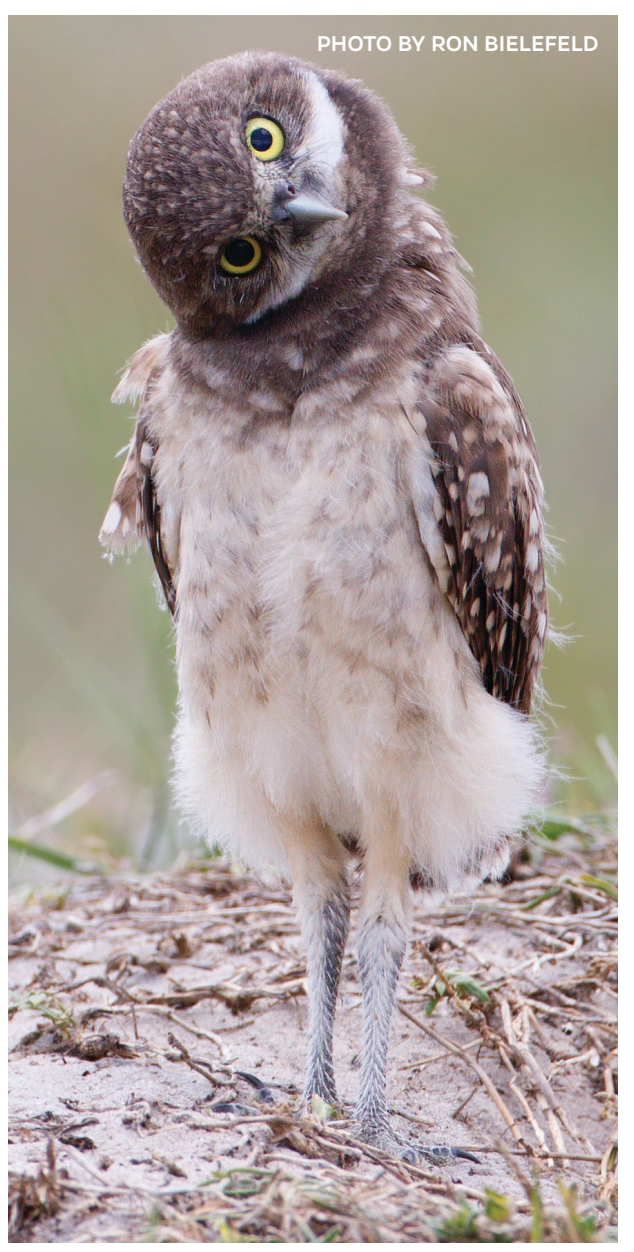

\section{More information and factsheots at edisoifasuflocdu}

